\title{
Mesenchymal Differentiation and Organ Distribution of Established Human Stromal Cell Lines in NOD/SCID Mice
}

\author{
Karin Thalmeier ${ }^{a}$ Petra Meissner ${ }^{b}$ Sabine Moosmann ${ }^{a}$ Sabine Sagebiela \\ Irmgard Wiest $^{c}$ Ralf Huss $^{a}$
}

a Institute of Pathology, University of Munich; b Micromet AG, Munich; 'Department of Otorhinolaryngology, Head and Neck Surgery, Klinikum r. d. Isar, Technische Universität, Munich, Germany

\section{Key Words}

Stromal cells · Mesenchymal stem cell · Osteoblast · Osteogenesis

\begin{abstract}
Two human stromal cell lines were established previously from bone marrow-derived primary long-term cultures by immortalization using the SV40 large T antigen and cellular cloning. After irradiation, the fibroblast-like cell lines L87/4 and L88/5 support hematopoietic differentiation of allogeneic cord blood cells in vitro. The stromal cells do not express CD34 and CD50, but some adhesion molecules and integrins, such as CD44, CD54 and CD58. Their expression profiles on RNA and protein levels are suggestive of their osteogenic potency. The quality and quantity of osteocalcin and osteopontin protein expression depended on the culture conditions. Expression of the osteogenic markers increased over time in culture, especially in cells growing in clusters. The stromal cells also expressed collagens I and V, but did not show any expression of collagens II and III. The potentially osteoblastic stromal cells were transplanted into NOD/
\end{abstract}

\section{KARGER}

Fax +41613061234

E-Mail karger@karger.ch

www. karger.com
(C) 2001 S. Karger AG, Basel

0001-5792/01/1053-0159\$17.50/0

Accessible online at:

www.karger.com/journals/aha
SCID recipient mice by intravenous injection and were found in various mesenchymal organs up to 10 weeks after transplantation. Osteocalcin-positive human stromal cells could be detected in the bone marrow, thymus, liver, brain and gut of the recipient animals. In summary, there is evidence that human bone-marrow-derived stromal cells have to be considered mesenchymal progenitors, persistently expressing osteogenic markers in vitro and in vivo.

Copyright @ 2001 S. Karger AG, Basel

\section{Introduction}

In recent years, there has been increasing interest in the plasticity of hematopoietic stem cells. In traditional understanding, hematopoietic differentiation requires the support by growth factors provided by stromal cells. Stromal cells are the major source of essential growth factors and part of the stromal cell system which also consists of mesenchymal stem cells and its progeny, connective tissue cells and intercellular matrix proteins [1]. For many years, bone marrow was considered to consist of three 
individual cellular components: hematopoietic, endothelial and stromal cells. The mesenchymal stem cells within the stromal compartment can differentiate into various connective tissue lineages including osteogenic precursors [2].

Stromal cells were defined as a fibroblast-like, adherent cell population obtained by direct plating of bone marrow cells. The diversity of marrow stroma components depends on culture conditions and growth media. Using a standard colony-forming unit-fibroblast (CFU-F) assay, we generated a monoclonal stromal cell line from canine bone marrow after immortalization of the adherent cells with a human papilloma vIrus 16 E6E7 construct $[3,4]$. From this CD34-negative cell line designated D064 we generated CD34-positive, nonadherent hematopoietic progenitors which also form other hematopoietic CFUs. D064 cells can also function as 'classical' stromal cells supporting the growth of allogeneic hematopoietic differentiation in vitro. This supports the notion that a stromallike cell population can give rise to hematopoietic progeny. A similar statement was made by Huang and Terstappen in their controversial paper, proposing that a single CD34-positive stem cell gives rise to CD34-negative stromal cells as well as to committed hematopoietic precursors $[5,6]$.

Since most of the CD34-negative fibroblast-like stromal cells are predominantly quiescent and refractory to external signalling, only a very small number of them can differentiate into hematopoietic progenitors. The majority of CD34-negative stromal cells are not committed to hematopoiesis, but can maintain and fulfil other functions. Here we investigated, whether two well-established human stromal cell lines function as mesenchymal stem cells and display an osteogenic potency in vitro and in vivo.

\section{Material and Methods}

\section{FACS Analysis}

The established human stromal cell lines L87/4 and L88/5 cells were detached from culture flasks by collagenase/dispase $(1 \mathrm{mg} / \mathrm{ml}$, Boehringer, Mannheim), washed with culture medium, counted and adjusted to appropriate cell concentrations. 5-10 $\times 10^{5}$ cells were used for FACS analysis. Cells were washed twice with IF buffer $(2 \%$ FCS, $0.01 \% \mathrm{NaN}_{3}$ in PBS) and incubated with the antibodies to be analyzed for $30 \mathrm{~min}$ at $4{ }^{\circ} \mathrm{C}$. Excessive antibody was removed by washing the cells twice with cold IF buffer. Cells were then incubated for $30 \mathrm{~min}$ at $4^{\circ} \mathrm{C}$ with a secondary PE or FITC-labeled antibody, washed twice with cold IF buffer, resuspended in $1 \mathrm{ml}$ IF buffer and analyzed in a flow-cytometer (Becton Dickinson, CellQuest).
Osteocalcin and Osteopontin m-RNA Detection by RT-PCR

One microgram total cellular RNA isolated from monolayers of L87/4 and L88/5 cells (Trizol, Gibco) was reverse transcribed by MMuLV reverse transcriptase (Promega) in a $10-\mu 1 \mathrm{RT}$ assay $(1 \mathrm{mM}$ dNTPs, $1 \times$ RT buffer, $100 \mathrm{ng}$ oligo(dT) $)_{15}, 10 \mathrm{U}$ RNasin, $100 \mathrm{U}$ M-MuLV RT) for $1 \mathrm{~h}$ at $42^{\circ} \mathrm{C}$. PCR was performed in $25-\mu 1$ reactions with $5 \mu \mathrm{l}$ of the RT product, 5 pmol of each primer (osteocalcin sense: 5'-ATGAGAGCCCTCACACTCCTCG-3'; osteocalcin antisense: 5'-CCGGGCCGTAGAAGCGCCGATA-3'; osteopontin sense: 5'-CATTGACTCGAACGACTCTG-3', osteopontin antisense: $5^{\prime}$-ACGGCTGTCCCAATCAGAAG- $3^{\prime}$ ) and $0.75 \mathrm{U}$ Taq Polymerase (Sigma). cDNA was amplified in 40 cycles $\left(58^{\circ} \mathrm{C}\right.$ annealing temperature) followed by a final extension step $\left(72^{\circ} \mathrm{C}, 7 \mathrm{~min}\right)$ (thermocycler: Biozym). The amplified DNA was separated on a $1.2 \%$ agarose gel, stained with ethidium bromide and photographed. Verification of the yielded osteocalcin PCR product was performed by an internal restriction analysis.

Transplantation of L87/4 and L88/5 Cells into NOD/SCID Mice NOD/SCID mice were irradiated with 2 Gy and transplanted $3 \mathrm{~h}$ later with $2 \times 10^{6} \mathrm{~L} 87 / 4$ or $2 \times 10^{6} \mathrm{~L} 88 / 5$ cells by slow injection into the tail vein. Control animals were irradiated without transplantation. 3, 6, and 10 weeks posttransplantation, 2 animals of each group were sacrificed, organs were removed and imbedded in paraffin, sectioned $(1-2 \mu \mathrm{m})$ and analyzed immunohistochemically.

\section{Immunohistochemical Investigation of Paraffin-Embedded}

Tissues

Transplanted mice were sacrificed 3, 6, and 10 weeks posttransplantation and tissues were immediately fixed overnight in buffered $4 \%$ formalin. Fixed tissues were embedded into paraffin and 1- to $2-\mu \mathrm{m}$ sections were analyzed as follows: Deparaffinized slides were pretreated in TRS6 (target retrieval) solution in a microwave oven for $15 \mathrm{~min}$ at $800 \mathrm{~W}$. Unspecific antibody-binding sites were blocked by incubating the slides in 'protein block serum free' (DAKO) solution for $10 \mathrm{~min}$. Subsequently, slides were incubated with primary antibody (osteocalcin Biotrend, 1:300) for $60 \mathrm{~min}$ at room temperature and stained with an alkaline phosphatase coupled secondary antibody (enVision Labelled Polymer-AP, DAKO). Binding was visualized by incubating the slides in Fast $\operatorname{Red}^{\circledR}$ solution (Sigma) for $10 \mathrm{~min}$.

\section{Immunohistochemical Investigation of L87/4 and L88/5 Cells} Grown on Chamber Slides

L87/4 and L88/5 stromal cells were grown to $70 \%$ confluency in Iscove's $/ 10 \%$ FCS medium in chamber slides. Slides were fixed with $4 \%$ paraformaldehyde for $20 \mathrm{~min}$ and digested with proteinase $\mathrm{K}$ (1:1,000, Quiagen) for $15 \mathrm{~min}$ at room temperature. Unspecific antibody-binding sites were blocked by $50 \mathrm{~min}$ incubation in $20 \% \mathrm{FCS}$ at room temperature. Binding of primary antibodies (table 1) was performed at $4{ }^{\circ} \mathrm{C}$ overnight. Antibody binding was vizualized by the ABC-peroxidase method (Vector, Burlingame, Calif., USA) as described by the manufacturer. As positive controls for the primary antibodies, the SaOS-2 osteosarcoma cell line as well as primary cultures from human middle ear bone were analyzed. As negative controls primary endothelial cells, primary fibroblasts and $\mathrm{CHO}$ cells were used. 
Table 1. Antibodies against osteogenic markers

\begin{tabular}{lll}
\hline Epitope & Manufacturer & Dilution \\
\hline Osteocalcin & Biotrend & $1: 400$ \\
Collagen I & Quartett & $1: 50$ \\
Collagen II & Quartett & $1: 50$ \\
Collagen III & Quartett & $1: 75$ \\
Collagen V & Quartett & $1: 100$ \\
\hline
\end{tabular}

\section{Results}

Surface Expression of the Mesenchymal Stem Cell Markers in Human Stromal Cell Lines L87/4 and L88/5

To characterize the mesenchymal phenotype of L87/4 and L88/5 stromal cells, we analyzed the surface expression of known mesenchymal markers by FACS analysis. For the generation of these data both cell lines were grown in monolayer cultures without stimuli. As shown in table 2, L87/4 and L88/5 cells did not express CD50, a marker which has been described for stromal components giving rise to hematopoietic progeny, while CD50 is not found on mesenchymal progenitors. Quiescent L87/4 and L88/5 cells did not express typical differentiation markers like Mac1 (CD11b), CD34, or HLA-DR. Both cell lines were positive for the adhesion molecules ICAM-1 (CD54), LFA-3 (CD58) and HCAM (CD44), molecules known to be important for the interaction of mesenchymal stem cells with hematopoietic progenitors (table 2). According to their colony forming potential in soft agar [8], L87/4 and L88/5 cells expressed the surface markers CD10, CD13, and the CD29/CD49 family of integrins (table 2) which are characteristically found on CFU-F precursor cells.

Additionally, both cell lines produced a variety of growth factors (Il-1, IL-6, IL-7, IL-8, IL-11, LIF, M-CSF, SCF, G-CSF, GM-CSF) known to be essential for a function as feeder layers in long-term cultures of hematopoietic cells [7].

\section{Osteogenic Potential of L87/4 and L88/5 Cell Lines}

In order to analyze the mesenchymal differentiation potential of L87/4 and L88/5 stromal cells, we first performed RT-PCR reactions specific for the osteogenic marker genes osteocalcin and osteopontin. As shown in
Table 2. Immunophenotype of L87/4 and L88/5 cells

\begin{tabular}{lll}
\hline & L87/4 & L88/5 \\
\hline Miscellaneous antigens & & \\
CD10 & ++ & + \\
CD13 & +++ & ++ \\
CD33, CD34, CD36, CD38, CD56 & - & - \\
CD68 & + & - \\
CD71 & +++ & ++ \\
HLKA-DR, glycophorin A & - & - \\
Fc-receptors & & \\
CD16, CD23, CD32, CD64 & - & - \\
Adhesion molecules & & \\
CD11a, CD11b, CD11c, CD18 & - & - \\
CD29 & +++ & +++ \\
CD44 & +++ & +++ \\
CD49b & ++ & + \\
CD49d & ++ & - \\
CD49e & +++ & +++ \\
CD49f & +++ & +++ \\
CD54 & +++ & ++ \\
CD58 & +++ & +++ \\
CD50, CD61, CD62E, CD102, CD106 & - & - \\
\hline
\end{tabular}

figure 1, both cell lines expressed osteocalcin as well as osteopontin mRNA.

Osteocalcin protein expression was demonstrated by immunohistochemistry. As positive control we used the osteocalcin-expressing human osteosarcoma cell line SaOS-2 and primary cultures from middle ear bones. Depending on culture conditions, varying percentages of L87/4 and L88/5 cells stained positive for osteocalcin (fig. 2).

Cells belonging to the osteogenic differentiation pathway are expected to express collagens I and $\mathrm{V}$ while being negative for collagens II and III. To characterize the osteogenic potential of L87/4 and L88/5 stromal cells, we analyzed the expression of collagen I, II, III, and V immunohistochemically. To generate these data, the cell lines were grown in monolayers on chamber slides without any stimuli. The osteosarcoma cell line $\mathrm{SaOS}-2$ as well as primary cultures of middle ear bones served as positive controls. As expected, SaOS-2 cells (fig. 3) and primary osteogenic cells stained positive for collagens I and V, while they did not show any signal for collagens II and III. Analyzed with these highly specific antibodies, L87/4 and L88/5 cells strongly express the typical osteogenic markers collagen I and $\mathrm{V}$, while we did not get any signal on the cells with antibodies against collagens II and III (fig. 3). 

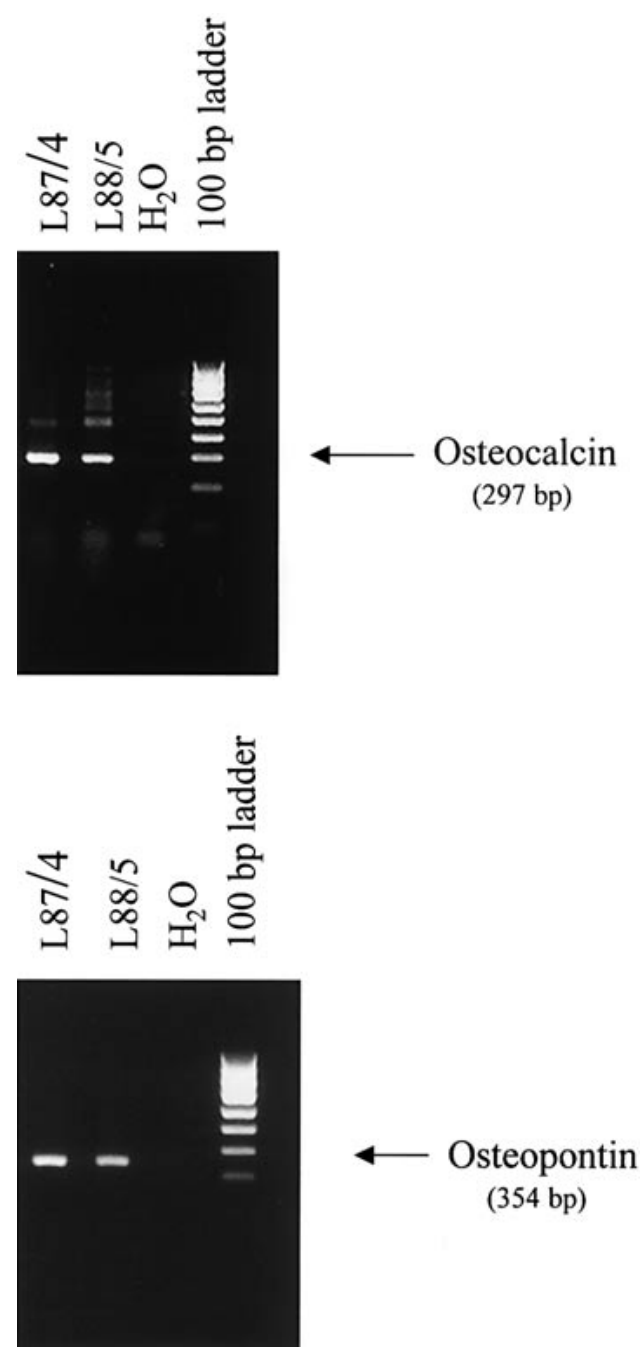

Fig. 1. Osteocalcin and osteopontin expresssion in L87/4 and L88/5 cells. $1 \mu \mathrm{g}$ of total RNA of L87/4 and L88/5 cells was analyzed by RT-PCR using primers against osteocalcin and osteopontin. PCR products were separated on $1.2 \%$ agarose gels and visualized by ethidium bromide staining.

Organ Distribution of L87/4 and L88/5 Cells in NOD/SCID Mice

Accumulating experimental evidence shows that mesenchymal stem cells are able to differentiate into a variety of organ-specific cell types after transplantation into NOD/SCID mice. To analyze the capacity of organ-spe- cific homing and differentiation of L87/4 and L88/5 cells, we transplanted both cell lines into irradiated NOD/SCID mice. Organs of the transplanted mice were collected 3, 6 and 10 weeks posttransplantation, embedded into paraffin and stained immunohistochemically. To show the differentiation status of the human transplants in murine tissue background, we used a human-specific antibody against osteocalcin. Since osteocalcin-positive cells seemed to persist at an extremely low number, we also stained the slides with an antibody against SV40 large T antigen as an additional specific marker for the transplanted human cells. We could show that up to 10 weeks posttransplantation both cell lines persisted in the bone marrow, the brain, the liver, the thymus and the gut of the transplanted animals (fig. 4).

\section{Discussion}

The two well-established human stromal cell lines L87/ 4 and L88/5 are commonly used to support human hematopoietic cells in vitro [7, 8]. Some years ago, it was already reported that STRO- $1^{+}$adult human bone marrow contains osteogenic precursors [9]. To test the hypothesis of a common population of stromal, mesenchymal stem cells and even hematopoiesis, we investigated the osteogenic potential of the two stromal cell lines mentioned above. The phenotypic analysis revealed an expression pattern common of established stromal cell lines, but, additionally, the expression of osteogenic markers such as osteocalcin and osteopontin in a certain number of the stromal cells $[10,11]$. Expression of the osteogenic markers increased over time in culture, especially in cells growing in clusters. Both cell lines, L87/4 and L88/5, expressed type $\mathrm{I}$ and type $\mathrm{V}$ collagen, indicative of bone precursors $[12,13]$, while they did not show any expression of types II and III collagens. This is suggestive for traditional stromal cells having the potential to function as osteogenic progenitors. After transplantation into NOD/SCID mice, human stromal cells also persisted in various mesenchymal organs. Human osteocalcin-positive L87/4 and L88/5 cells were not only found in capillary vessels of the lung, liver and bone marrow, but were also well suited in the thymus and the central nervous system. Therefore, human bone marrow-derived stromal cells have to be considered mesenchymal precursors which can persist in various organ sites of the recipient animals. The importance of these data becomes clear in view of the current discussion about the plasticity of stem cells [14], since these pluripotent stem cells can be isolated from various tissues

$\overline{162} \quad \overline{\text { Acta Haematol 2001;105:159-165 }}$

Thalmeier/Meissner/Moosmann/Sagebiel/ Wiest/Huss 
Fig. 2. Immunohistochemical staining of osteocalcin in SaOS-2 and L88/5 cells SaOS-2 and L8875 cells were grown on chamber slides, fixed, air-dried and incubated with a polyclonal antibody against osteocalcin. Antibody binding was visualized by the $\mathrm{ABC}$ peroxidase method. A high percentage $(>80 \%)$ of SaOS-2 cells were positive for osteocalcin, while L88/ 5 cells showed variable protein expression, depending on the cell cycle status.

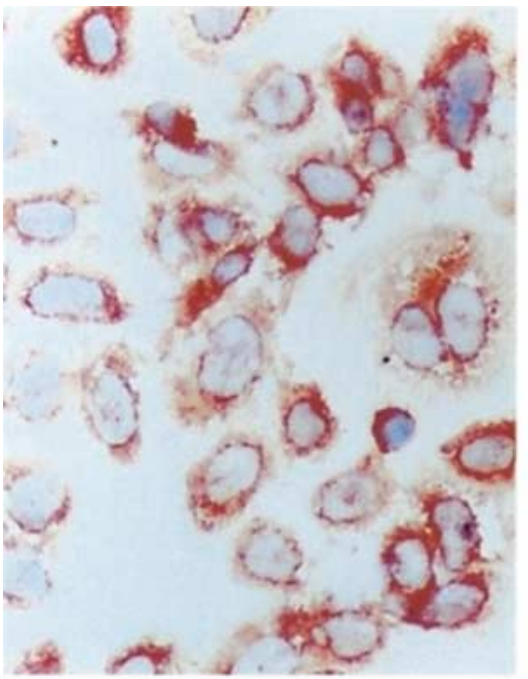

SaOS-2

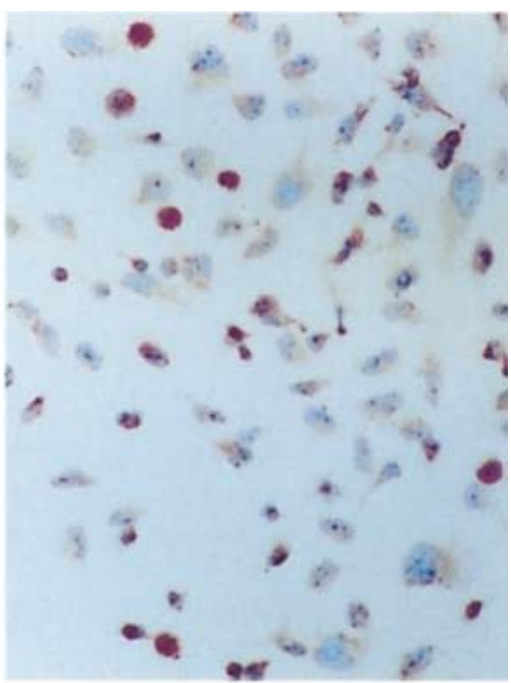

$\mathrm{L} 88 / 5$
Collagen I
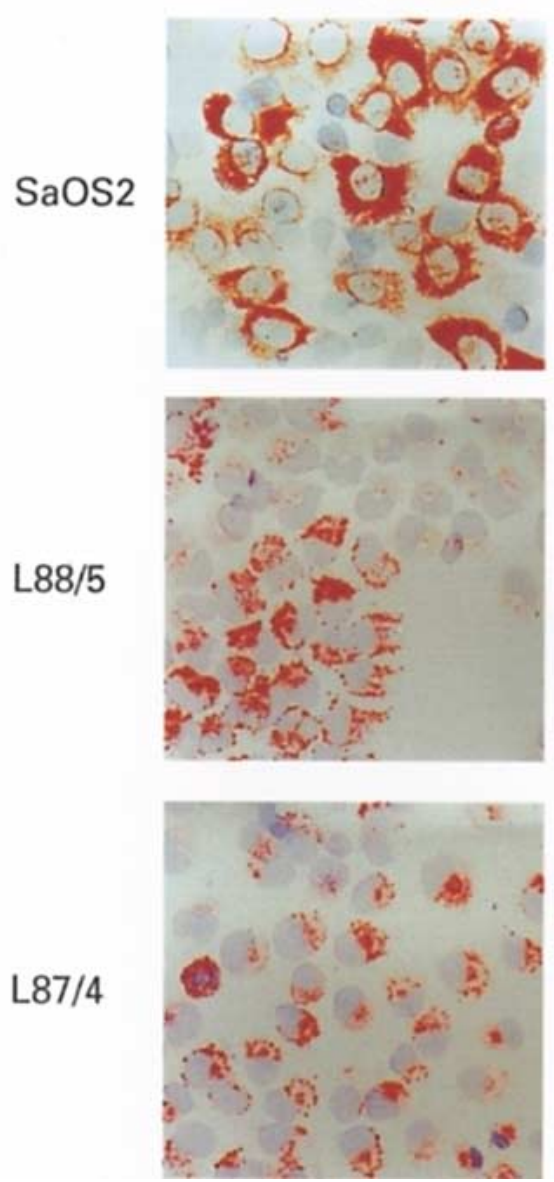

Collagen III
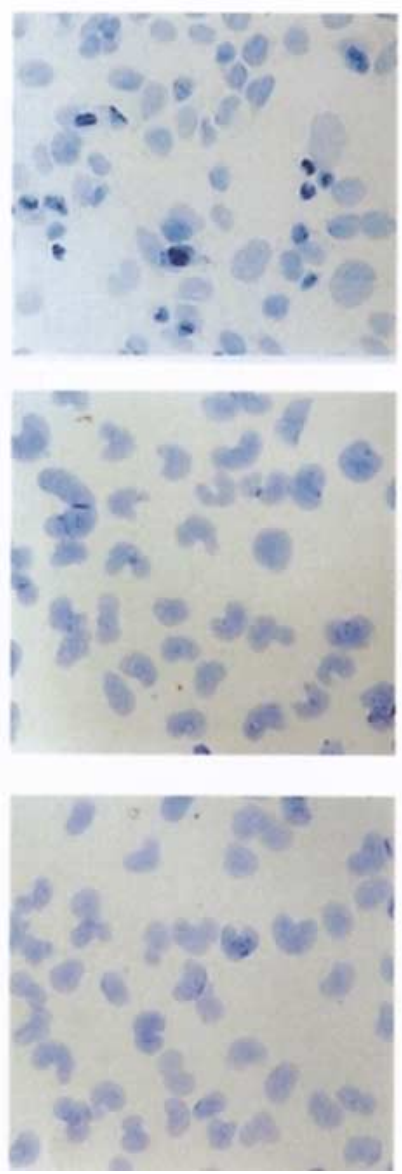

Collagen V
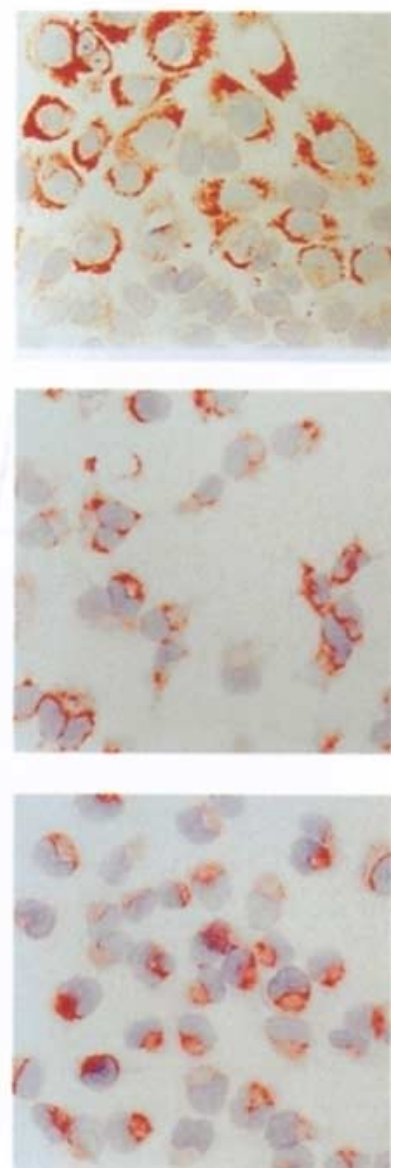

Fig. 3. Collagen expression of SaOS-2, L87/4 and L88/5 cells SaOS2 , L87/4 and L88/5 cells were grown in monolayer cultures on chamber slides, fixed in paraformaldehyde and air-dried. Cells were incubated with antibodies against collagens I, II, III and V and binding was visualized by the $\mathrm{ABC}$-peroxidase method. All three cell lines showed a collagen expression pattern typical for cells of the osteogenic differentiation pathway, positive for collagens I and V, negative for collagens II and III. 


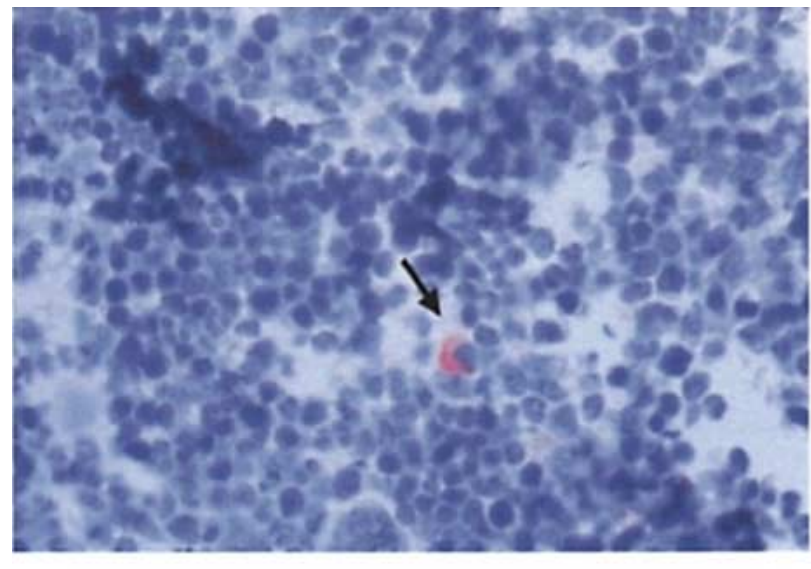

bone marrow

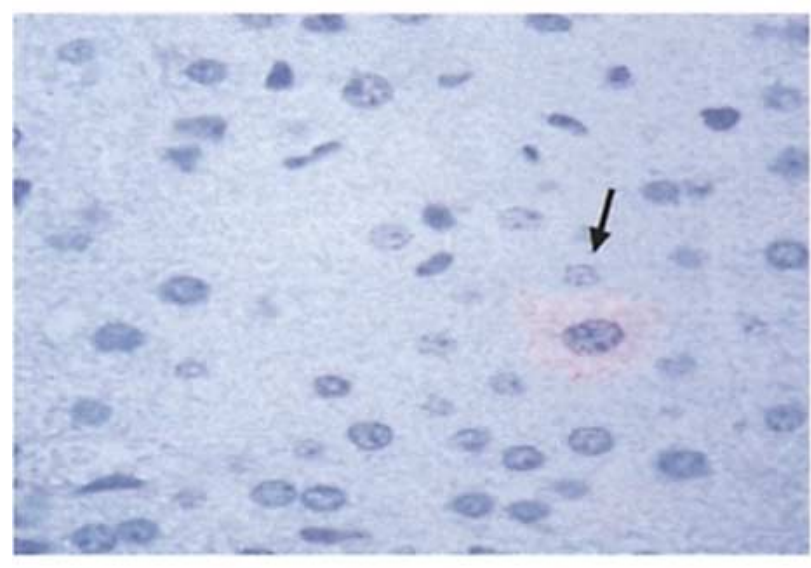

liver

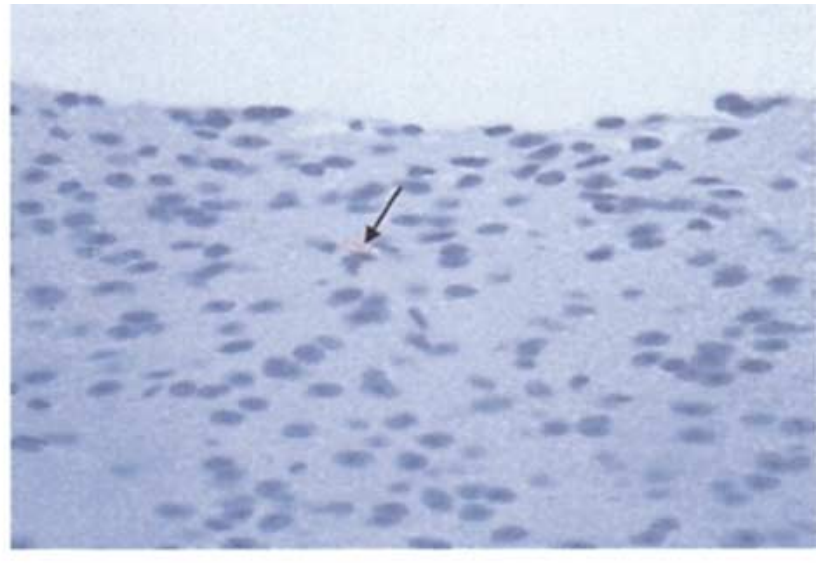

brain

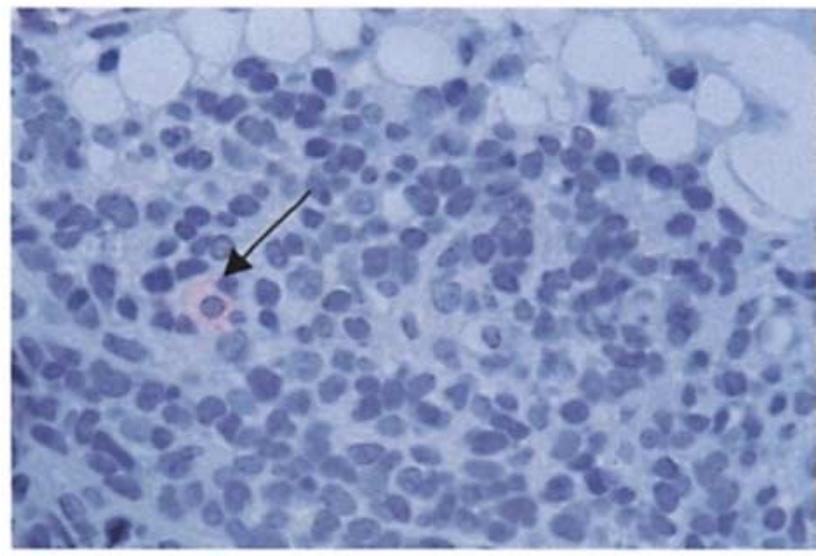

thymus

Fig. 4. Immunohistochemical detection of transplanted L87/4 cells in different tissues of NOD/SCID mice. NOD/SCID mice were transplanted with L87/4 cells and sacrificed 10 weeks posttransplantation. Murine tissues were imbedded into paraffin, sectioned and analyzed immunohistochemically. As indicated above (arrow), single osteocalcin-positive L87/4 cells were present in the bone marrow, thymus, liver and brain of the transplanted animals

and even peripheral blood where they exist as circulating stem cells [15-17].

As of yet, hematopoietic and repopulating stem cells have been identified by surface expression of CD34 antigen. There were some publications in recent years demonstrating that CD34-negative cells can also reconstitute the complete lympho-hematopoietic system of mice and sheep [18-22]. Although evidence is controversial, stromal cells as well as mesenchymal stem cells are considered to be CD34-negative [23]. Our own experiments showed that CD34-positive hematopoietic progenitors can be generated from CD34-negative, stroma-like precursors [24].
In culture, approximately $0.1 \%$ of the L87/4 and L88/5 stromal cells express CD34 even spontaneously [unpubl.]. The phenotype of a mesenchymal cell line seems to depend on cell culture conditions. Grown in monolayer cultures, our two cell lines do not express CD50 and CD34 while they are positive for CD44, CD49e and CD49f. This expression pattern is consistent with the phenotype of described mesenchymal cells [1]. According to other reports, mesenchymal stem cells express CD106 (VCAM), but are negative for CD49d. VCAM was not found in either cell line, L87/4 and L88/5, but the former was positive for CD49d. Depending on cell culture condi- 
tions, different phenotypes of mesenchymal precursor cells could be observed, although the cell lines are morphologically and functionally closely related.

Recent reports suggested the clinical use of mesenchymal stem cells isolated from bone marrow [25]. Our results provide further evidence that even marrow stromal cell lines can be used to generate distinct mesenchymal organ tissue such as bone tissue, depending on cell culture conditions. Most of the growth factors which play a pivotal role in directing differentiation of quiescent stem cells towards specialization are produced in an autocrine and paracrine fashion by stromal cells $[7,26]$. Therefore, stromal cells might be the essential link between mesenchymal stem cells and quiescent hematopoietic progenitors which we could identify as CD34-negative, fibroblast-like cells [27, 28]. It is even probable that there is a common progenitor cell to all three cell types, the function of which is determined by the ultimate demand within an organism.

\section{References}

1 Deans RJ, Mosley AB: Mesenchymal stem cells: Biology and potential clinical uses. Exp Hematol 2000;28:875-884.

2 Majors AK, Boehm CA, Nitto H, Midura RJ, Muschler GF: Characterization of human bone marrow stromal cells with respect to osteoblastic differentiation. J Orthopaed Res 1997;15: 546-557.

3 Huss R, Hong DS, McSweeney PA, Hoy CA, Deeg HJ: Differentiation of canine marrow cells with hematopoietic characteristics from an adherent stromal cell precursor. Proc Natl Acad Sci USA 1995;92:748-752.

4 Huss R, Hoy CA, Deeg HJ: Stroma derived hematopoietic progenitors: Cell cycle dependent proliferation and differentiation; in Gluckman E, Coulombel E (eds): Ontogeny of Hematopoiesis. Aplastic Anemia. Colloque Inserm. Paris, Libbey Eurotext,1995, vol 235, pp 209-213.

5 Huang S, Terstappen LWMM: Formation of hematopoietic microenvironment and hematopoietic stem cells from single human bone marrow stem cells. Nature 1992;360:745-748.

6 Huang S, Terstappen LWMM: Formation of hematopoietic microenvironment and hematopoietic stem cells from single human bone marrow stem cells (correction). Nature 1994;368: 364.

7 Thalmeier K, Meissner P, Reisbach G, Hültner L, Mortenson BT, Brechtel A, Oostendorp RAJ, Dörmer P: Constitutive and modulated cytokine expression in two permanent human bone marrow stromal cell line. Exp Hematol 1996;24:1-9.

8 Thalmeier K, Meissner P, Reisbach G, Fak M, Brechtel A, Dörmer P: Establishment of two permanent bone marrow stromal cell lines with long-term post-irradiation feeder capacity. Blood 1994;83:1799-1807.

9 Gronthos S, Graves SE, Ohta S, Simmons PJ: The STRO-1+ fraction of adult bone marrow contains osteogenic precursors. Blood 1994;84: 4164-4173.
10 Lajeunesse D, Kiebzak GM, Frondoza C, Sacktor B: Regulation of osteocalcin secretion by human primary bone cells and by the human osteosarcoma cell line MG-63. Bone Miner 1991;14:237-250.

11 Morike M, Schulz M, Brenner RE, Bushart GB, Teller WM, Vetter U: In vitro expression of osteoblastic markers in cells isolated from normal fetal and postnatal human bone and from bone of patients with osteogenesis imperfecta. J Cell Physiol 1993;157:439-444.

12 Bidwell JP, Alvarez M, Feister H, Onyia J, Hock J: Nuclear matrix proteins and osteoblast gene expression. J. Bone Miner Res 1998;13: 155-167.

13 Chesney J, Bacher M, Bender A, Bacula R: The peripheral blood fibrocyte is a potent antigenpresenting cell capable of priming naive $T$ cells in situ. Proc Natl Aacd Sci USA 1997;94:63076312.

14 Prockop DJ: Marrow stromal cells as stem cells for nonhematopoietic tissue. Science 1997;276: 7174.

15 Huss R, Lange C, Weissinger EM, Kolb HJ, Thalmeier K: Evidence of peripheral bloodderived, plastic adherent CD34-/low hematopoietic stem cell clones with mesenchymal stem cell characteristics. Stem Cells 2000;18: 252-260.

16 Ferrari G, Cusella-De Angelis G, Coletta M, Paolucci E, et al: Muscle regeneration by bone marrow-derived myogenic progenitors. Science 1998;279:1528-1532.

17 Huss R, Günther W, Schumm M, Ottinger H, Grosse-Wilde H, Kolb HJ: CD34-negative hematopoietic stem cells isolated from human peripheral blood cells as ultimate precursors of hematopoietic progenitors. Infusionsther Transfusionsmed 1997;24:404-409.

18 Lange C, Kaltz C, Thalmeier K, Kolb HJ, Huss $\mathrm{R}$ : Hematopoietic reconstitution of syngeneic mice with a peripheral blood-derived, monoclonal CD34-, Sca-1 ${ }^{+}$, Thy-1 ${ }^{\text {low }}$, c-kit $^{+}$stem cell line. J Hematother 1999;8:335-342.

19 Osawa M, Hanada K, Nakauchi H: Long-term lymphohematopoietic reconstitution by a single CD34-low/negative hematopoietic stem cell. Science 1996;273:242-245.
20 Zanjani ED, Almeida-Porada G, Livingston AG, Flake AW, Ogawa M: Human bone marrow CD34-negative cells engraft in vivo and undergo multilineage expression that includes giving rise to CD34+ cells. Exp Hematol 1998; 26:353-358.

21 Bhatia M, Bonnet D, Murdoch B, Gan OI, Dick JE: A newly discovered class of human hematopoietic cells with SCID-repopulating activity. Nat Med 1998;9:1038-1045.

22 Goodell MA, Brose K, Paradis G, Conner AS, Mulligan RC: Isolation and functional properties of murine hematopoietic stem cells that are replicating in vivo. J Exp Med 1996;183:17971806.

23 Simmons PJ, Torok-Storb B: CD34 expression by stromal precursors in normal human adult bone marrow. Blood 1991;78:2848-2853.

24 Huss R: CD34-negative stem cells as the earliest precursors of hematopoietic progeny. Exp Hematol 1998;26:1022-1023.

25 Horwitz, E.M. Prockop DJ, Fitzpatrick LA, Koo WWK, Gordon PL, Neel M, SussmanM, Orchard P, Marx JC, Pyeritz RE, Brenner MK: Transplantability and therapeutic effects of bone marrow-derived mesenchymal cells in children with osteogenesis imperfecta. Nat Med 1999;5:309-313.

26 Huss R, Hoy CA, Deeg HJ: Contact and growth factor involved in proliferation and differentiation in a canine marrow-derived stromal cell line. Blood 1995;85:2414-2421.

27 Huss R, Gatsios P, Graeve L, Lange C, Eissner G, Kolb HJ, Thalmeier K, Heinrich PC: Quiescence of CD34-negative hematopoietic stem cells is mediated by downregulation of cyclin B and no STAT activation. Cytokine 2000; 121195-1204.

28 Singer JW, Keating A, Cuttner J, Gown AM, Jacobson R, Killen PD, Moohr JW, Najfeld V, Powell J, Sanders J, Striker GE, Fialkow PF: Evidence for a stem cell common to hematopoiesis and its in vitro microenvironment: Studies of patients with clonal hematopoietic neoplasia. Leuk Res 1984;8:535-539. 